\title{
Cross-Border Electronic Commerce Development Present Situation and the Innovation Research in China
}

\author{
Wenjuan He, Yuming Xu \\ School of Business Administration, South China University of Technology, Guangzhou, China \\ Email: 13662424743@163.com
}

How to cite this paper: $\mathrm{He}, \mathrm{W} . J$. and $\mathrm{Xu}$, Y.M. (2018) Cross-Border Electronic Commerce Development Present Situation and the Innovation Research in China. American Journal of Industrial and Business Management, 8, 1825-1842.

https://doi.org/10.4236/ajibm.2018.88124

Received: August 1, 2018

Accepted: August 25, 2018

Published: August 28, 2018

Copyright $\odot 2018$ by authors and Scientific Research Publishing Inc. This work is licensed under the Creative Commons Attribution International License (CC BY 4.0).

http://creativecommons.org/licenses/by/4.0/

\begin{abstract}
With the opening of China's national gate, China's economy has entered a stage of rapid development, and the development of cross-border e-commerce is extremely strong, which has greatly impacted and affected the international trade market. The article is organized as follows 3 parts: based on the summary of the new development trend of global e-commerce, this paper analyzes and studies the different aspects of how to conduct innovation in e-commerce according to China's national conditions and the status quo of China's e-commerce trade, and finally obtains innovation research in China. The new trend includes innovation of profit model, innovation of marketing model and innovation of supervision mode; China's e-commerce innovation is characterized by diversified development of profit model, and enhances competitiveness and marketing mode through integration of value-added services with logistics and supply chain. Including B2C mode, direct supply mode, $\mathrm{B} 2 \mathrm{~B}$ mode and Amazon integration, $\mathrm{B} 2 \mathrm{~B}$ and $\mathrm{B} 2 \mathrm{C}$ access, and the innovation of supervision mode should be the conclusion of the comprehensive management of relevant ministries and commissions, joint management and unblocking of various functional departments.
\end{abstract}

\section{Keywords}

Electronic Commerce, New Trend, Innovation

\section{Introduction}

With the continuous development of science and technology, e-commerce has gradually penetrated into our daily life. Since the $21^{\text {st }}$ century, e-commerce has developed rapidly as an emerging industry, which has greatly impacted traditional trade methods. E-commerce trade not only simplifies the traditional way 
of trade, but also improves the efficiency of economic turnover, while reducing the cost of trade, and has played a powerful role in promoting the development of international trade.

As an exporting country with economic and trade, e-commerce has brought us a great development opportunity-to raise the strategic position of China's foreign trade to a new height; it also brings challenges-e-commerce market. The competitiveness will be bigger and bigger, and with the foreign market will have a certain impact on the Chinese market. China's own development in the e-commerce market because of the speed is too fast, there have been many problems, such as: market disorderly development, lack of supervision, logistics system is not perfect.

At the same time, Chinese scholars have also analyzed cross-border e-commerce from different perspectives. For example, in the logistics transportation system of cross-border electronic trade, Cao Shuyan (2013) used the syllogism method to conduct research and analysis on cross-border e-commerce logistics, focusing on the cross-border e-commerce third-party logistics model [1]; Zhang Xiaheng and Guo Hailing (2016) used different perspectives such as species, environment, supply chain and geospatial explore the synergy mechanism between cross-border e-commerce and cross-border logistics [2]. In addition, as for the payment system, Xiao Chengzhi and Bian Wenting (2016) have studied the cross-border payment settlement of domestic and foreign currencies closely related to cross-border e-commerce in China in the context of the new normalization of the internationalization of RMB in recent years and the increase in the proportion of cross-border RMB denomination settlement. The form of liquidation is analyzed [3].

Foreign experts and scholars usually combine in-depth research on cross-border e-commerce and trade growth. Satis Chandra Devkota used computer software to establish a data model. The factors affecting the country's export trade were studied in two aspects: first, product breadth, and second, product depth. American scholar Davidvan Hoose studied e-commerce and the global trading system in E-Commerce Economics, and concluded that economies of scale and imperfect competition can better understand and comprehend e-commerce trade [4].

This paper summarizes the four aspects of global e-commerce development, and studies the development and innovation of cross-border e-commerce in China from four aspects: profit model, marketing model, big data management and supervision mode. The development of China and its trade innovation have realistic significance.

\section{The New Development Trend of Global E-Commerce}

\subsection{Internet Companies}

The integration of e-commerce companies and Internet companies. Today's global Internet companies and large and small Internet companies are at a stage centered on the value chain. E-commerce websites have gradually formed a situ- 
ation of mutual cooperation and merger. For example, the mutual merger of Alibaba and the US Mission, the merger of Suning Tesco and Alibaba, the cooperation between Dangdang and Taobao, etc., the types, positioning and core concepts of these websites are similar, and the products given to consumers are also very similar. Therefore, cooperation and mergers between online e-commerce websites can not only reduce competition, achieve win-win, but also enhance the competitiveness between cooperative companies. Each e-commerce enterprise has its own advantages and disadvantages. Merger and cooperation can play a role in fostering strengths and avoiding weaknesses, and each advantage can maximize benefits.

\subsection{Business Diversification}

The business of e-commerce companies tends to be more diversified. The Amazon website in the United States was founded in 1995. In addition to music and books, there are quite a few types that can satisfy the consumer needs of various consumers. At the same time, it gradually launched third-party open platforms, network services, Prime services, outsourcing logistics services to third-party sellers, self-service digital publishing platforms and other services, which made it beyond the scope of online retailers and became an integrated service provider. China's Jingdong Mall officially entered the e-commerce field in 2004. At the beginning of its establishment, it only positioned the website to sell household appliances. Today, Jingdong sells a wide variety of products, relying on the unique advantages of Jingdong logistics and service quality. It has maintained a high growth rate in the field of e-commerce.

\subsection{Trading Terminal Mobilization}

Between 2011 and 2016, global online retail transactions increased from US\$860 billion to US $\$ 192$ billion, with an average annual growth rate of $17.4 \%$ [5]. In the first half of 2017, the scale of cross-border e-commerce transactions in China was 3.6 trillion yuan, a year-on-year increase of $30.7 \%$. Among them, the export cross-border e-commerce transaction scale was 862.4 billion yuan (including: imported B2B, B2C, C2C). In 2017, the total value of retail import and export through the customs cross-border e-commerce management platform reached 90.24 billion yuan, a year-on-year increase of more than $80 \%$ [6]. These amazing numbers are all due to the rapid development of mobile Internet, and consumers have more choices in mobile devices and payment methods when they consume online. Mobile devices have spurred the development of e-banking and various online payments, while at the same time bringing more convenient and faster services to online e-consumers.

\subsection{Payment Terminal Diversity}

Global e-commerce transaction payment methods tend to be diversified. Paypal, the world's largest payment service for online electronic transactions, was 
founded in the late 1990s. The company's initial stage was to receive consumers of international payments. By 2014, consumers of cross-border e-commerce transactions were using Paypal software. The number of people who consume is more than $87 \%$ of all cross-border e-consumers. Well-known websites in some countries around the world also work with Alipay to achieve cross-border payments. For example, in order to facilitate Chinese consumers to purchase Korean local products, Lotte Duty Free Shop in South Korea can choose Alipay to pay in the payment process, eliminating some currency exchange processes and making cross-border e-commerce more convenient. In 2014, Alipay reached a partnership with American online payment company, which provided great convenience for Chinese buyers' cross-border online consumption. In addition, today's Samsung and Apple have designed and applied NFC payment features. Through NFC technology, consumers' mobile phones can be used as a mobile payment tool for more convenient consumption.

\section{The Development Status of Cross-Border E-Commerce in China}

\subsection{Overview of Cross-Border E-Commerce in China}

1) Cross-border e-commerce transactions grow rapidly

According to survey data from the Ministry of Commerce of the People's Republic of China, the scale of cross-border e-commerce transactions in China in 2010 was 1.1 trillion yuan, growing year by year. In 2014, China's cross-border e-commerce transactions were 4.2 trillion yuan, a year-on-year increase of $33.3 \%$. The continuous expansion of China's e-commerce scale has enabled China's cross-border e-commerce industry to continuously adjust and upgrade.

According to the "2015 (I) China E-Commerce Market Data Monitoring Report", in the first half of 2015, China's e-commerce transaction volume reached 7.59 trillion yuan, a year-on-year increase of $30.5 \%$. From January to June, the ratio of $\mathrm{B} 2 \mathrm{~B}$ and $\mathrm{B} 2 \mathrm{C}$ transactions in China's cross-border e-commerce transactions was $91.9 \%$ and $8.1 \%$, respectively. Figure 1 shows the scale of cross-border e-commerce transactions in China from 2010 to 2015, and Figure 2 shows the proportion of $\mathrm{B} 2 \mathrm{~B}$ and $\mathrm{B} 2 \mathrm{C}$ transactions in China's cross-border e-commerce transactions from January to June 2015.

2) "cross-border online shopping" and "procurement service" develop rapidly

Due to the continuous development of technology, more and more netizens have emerged. With its low investment and convenient world transportation system, Haitao has become one of the most popular shopping modes in the world. With the expansion of cross-border e-commerce, the "cross-border online shopping" and "procurement service" in the global cross-border e-business have developed rapidly, and at the same time, it has brought development and competition.

The advantage of overseas shopping is that the product quality is good, the 


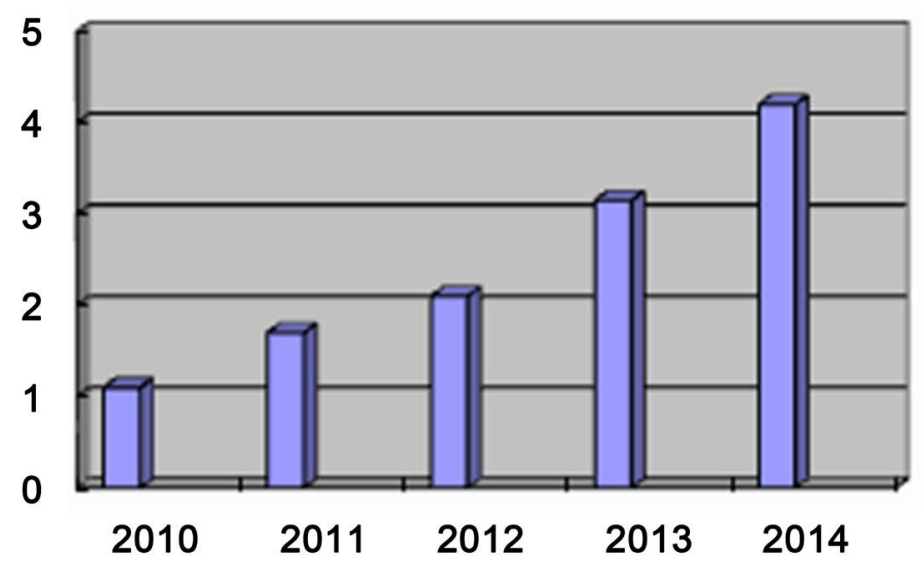

Figure 1. Scale of cross-border e-commerce transactions in China from 2010 to 2015 (unit: trillion yuan).
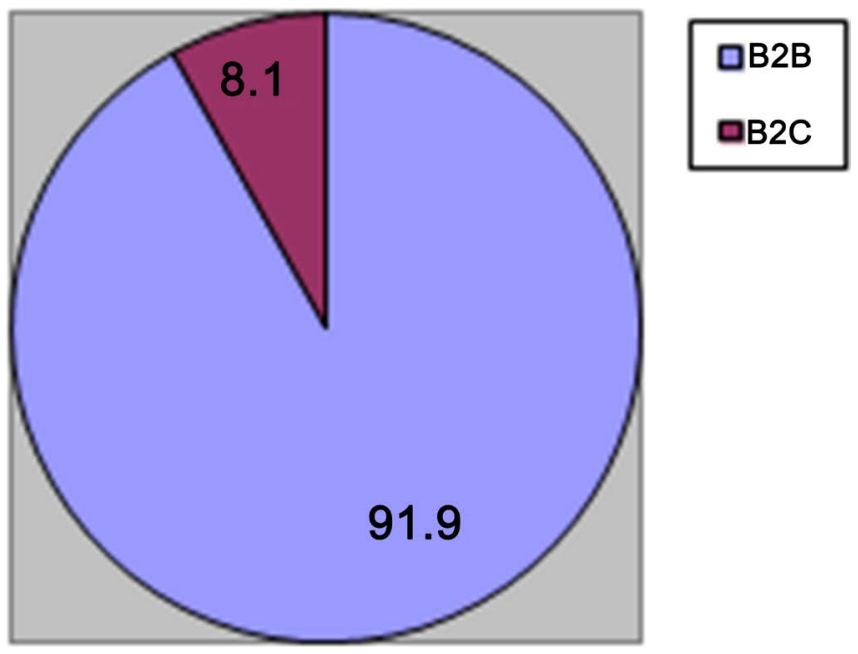

Figure 2. Proportion of B2B and B2C transactions in China's cross-border e-commerce trading model from January to June in 2015.

discount is much, and the brand is fashionable. The biggest advantage of "Hao Tao" is the safety of goods. In addition, due to the high domestic tax price and the high quality and low price of foreign goods, the "cross-border online shopping" group has begun to develop and expand rapidly. The purchasing process includes the search and selection of consumer goods, the selection of the purchasing store, and the payment of the price including the commodity price, the logistics fee and the purchasing fee after negotiation. After confirming the order and payment, the purchaser outside the country will purchase the goods according to the needs of the consumers, and consign the purchased goods back to the hands of the consumers. With the continuous development of cross-border e-commerce, there have been a number of vertical websites focusing on Haitao, such as 55 Haitao, Haitao Home, Haitao City and so on. These Haitao website organizations are more professional and systematic, and they can directly shop on foreign websites through Haitao website. They can gain the trust of users more than traditional purchasing. 


\subsection{Main Platform and Trading Methods for Cross-Border E-Commerce in China}

1) Main platform for cross-border e-commerce in China

There are many cross-border e-commerce platforms in China. The B2B platforms include Alibaba, Dalong.com, Yitang.com, China Manufacturing Network and Dunhuang. The B2C platforms mainly include AliExpress, Ebay, Amazon and "Light in the box". Dunhuang Network is the innovator of B2B, and the transaction volume has always maintained the first position in the Asia-Pacific region. "Light in the box" Gathering is constantly transforming with the department store-style operation mode. Therefore, this article will use "Light in the box" as the B2C representative. B2B represents separate exploration and analysis showing in Table 1.

2) "Light in the box"

"Light in the box" is a multinational B2C company founded in 2007. It is an online B2C that integrates supply chain services in China. The company has a range of suppliers and has its own data warehouse and long-term logistics partners. At the beginning of the establishment, the world was in the midst of a financial crisis. At the time, "Light in the box" positioned the company as an e-commerce integrated supply chain serving small and medium-sized enterprises around the world. Its main customers were from Europe and North America. In 2012, the proportion of foreigners among customers accounted for $98 \%$ of the total number of customers. In the initial stage of "Light in the box", its platform is mainly based on the marketing of electronic products, but the profit is relatively small. The company began the transformation path and began to expand the product range of its own trading platform, and began to turn to more profitable products, such as electronic accessories and clothing, and regularly adjust the product categories to maximize profits.

It uses a department store-style operating model:

a) Supply Chain Management: "Light in the box" has an extremely efficient management mode in the management of supply chain. This not only improves the turnover rate of funds and inventory, but also makes the output value of the enterprise huge, and there is no remaining inventory. "Light in the box" of custom-made products usually uses a dedicated team of experts to contact the supplier and directly transfer the actual guidance plan and operation plan with the production line, which greatly improves the quality of the product and also improves the quality. Efficiency, generally the entire process down time can be controlled in 10 - 15 days, and in the shortest time to the "light in the box" collection warehouse. When receiving the order, "light in the box" will collect the goods in the warehouse in advance, which can improve the delivery efficiency,

Table 1. Major cross-border e-commerce companies in China.

\begin{tabular}{cccccc}
\hline B2B & Made-In-China.com & Global Resources & Alibaba & DHGate.com & Dalong.com \\
B2C & Express & Amazon & Ebay & KJT.com & Light in the box \\
\hline
\end{tabular}


so that the products can reach the consumers faster, greatly improving the efficiency.

b) Marketing model: "Light in the box" is soaring development can be attributed to its successful network marketing model. "Light in the box" is not keen on the establishment of channel brands, but more emphasis on marketing methods that directly drive sales: engine marketing, email marketing and affiliate advertising programs, etc. The search engine is "Light in the box" most important marketing model, and Facebook is the main channel for "Light in the box" to launch a social marketing model. There are also many companies that have taken the initiative to find the "Light in the box" collection and proposed to jointly establish an alliance marketing plan to achieve the goal of mutual profit. So far, the number of websites that "Light in the box" has been advertising on the website has exceeded 100,000. This amazing number has also made "Light in the box" more and more users, which brings huge profits to the company.

c) Logistics and distribution: Like other cross-border e-commerce enterprises and companies, "Light in the box" still has certain problems in logistics and distribution, especially cross-border logistics and distribution. In the 2014 financial statements, its logistics expense rate was $4.89 \%$, but this data has some error with the actual situation, because the logistics cost in the data is the sum of the storage cost and the order payment cost, and the cost of order processing and logistics distribution is not included. If the logistics cost is calculated separately, the proportion is about $23.8 \%$. Although "Light in the box" gathers to ensure the quality of the products sold to reduce the return rate, cross-border logistics is always an important question is how important cross-border logistics is to B2C.

3) "DHGate.com"

"DHGate.com" is China's online foreign trade B2B platform, serving many small and medium-sized suppliers, collecting rent, free registration, providing them with the latest and most effective trade information. "DHGate.com" has organically integrated e-commerce and traditional international trade, and has become a well-deserved innovator of B2B2.0. According to statistics from the world's largest PayPal payment platform, the online transaction volume of "DHGate.com" has always been at the forefront of the Asia-Pacific region. The trading process of "DHGate.com" is as follows: First, the buyer selects the preferred product in "DHGate.com" online and pays through the Paypal payment platform; next, the seller confirms the cargo information and the buyer's request, prepares the goods; after that, the seller delivers the goods to the logistics company. The process; after that, the buyer receives the goods and confirms the receipt and payment; in the end, the "DHGate.com" will charge the seller's account and the transaction is completed.

\subsection{Major Export Market for Cross-Border E-Commerce in China}

According to a report released by PalPay in 2013, consumers in the US, Germany, and the United Kingdom like to buy products from China online. The author 
through the report data, the list is as follows: Figure 3 is the data of the world's major website hotspot countries, Figure 4 is the proportion of netizens who tend to shop in China. The US website is the hottest, but consumers who are interested in purchasing on the Chinese website account for the largest share of Germany, followed by the United States and Germany.

According to statistics, in the first five months of 2015, China exports to the United States reached US\$969.1 billion, an increase of $8.9 \%$ year-on-year. The United States remains China's largest export market, and in May 2015, exports to the United States reached a new high for the year, reaching 21.9 billion yuan, an increase of 7.6\% compared with May 2014. However, with the recovery of the world economy and the existence of many uncertain factors, resulting in more international competition, China's foreign trade is facing downward pressure. Table 2 shows the export value of China's important exporting countries in recent years. By 2014, China's exports to different regions have increased year by year. Table 2 shows the distribution ratio of China's exports in major Asian

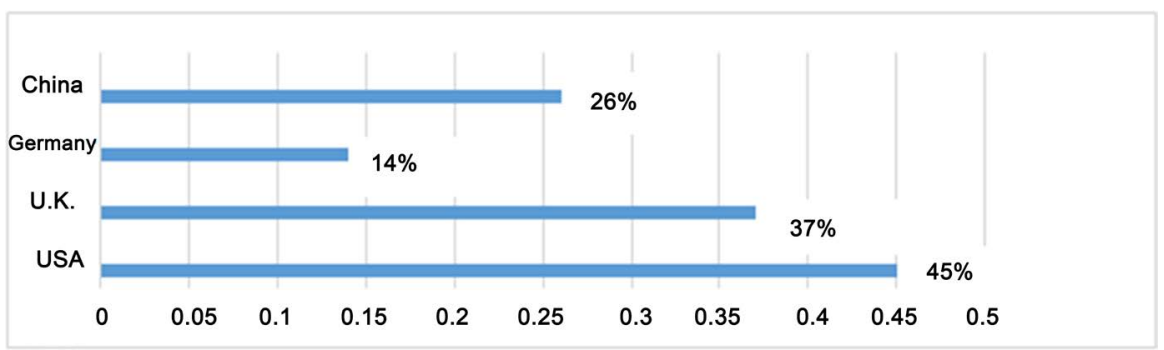

Figure 3. Global website popularity.

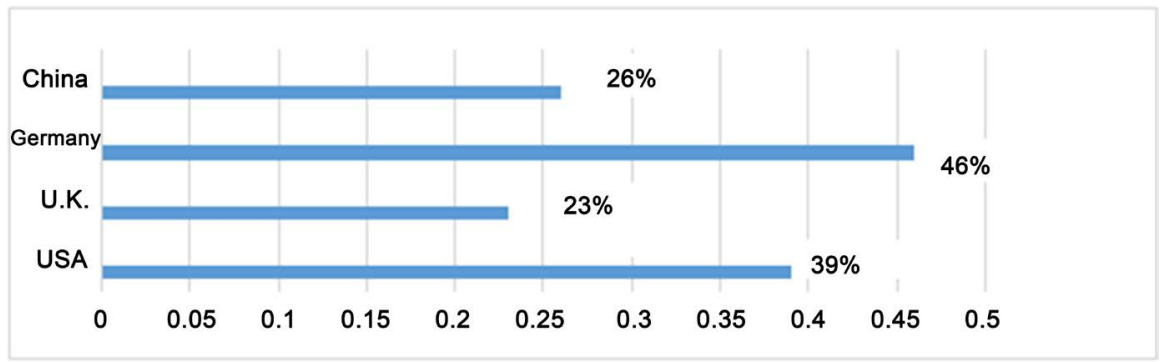

Figure 4. The proportion of consumers who are willing to purchase online on Chinese websites.

Table 2. Export amount of important export areas in China from 2010 to 2014.

\begin{tabular}{cccccc}
\hline & 2010 & 2011 & 2012 & 2013 & 2014 \\
\hline Japen & 1210.61 & 1482.98 & 1516.43 & 1502.75 & 1496.42 \\
Korea & 687.71 & 829.24 & 876.81 & 911.76 & 1003.40 \\
Hongkong & 2183.17 & 2680.25 & 3235.27 & 3847.92 & 3631.91 \\
ASEAN & 1382.07 & 1700.83 & 2042.72 & 2440.70 & 2720.71 \\
EU & 3112.35 & 3560.20 & 3339.89 & 3389.85 & 3708.84 \\
USA & 2833.04 & 3244.93 & 3517.96 & 3684.27 & 3960.82 \\
\hline
\end{tabular}


markets in 2014.

According to Table 2 and Figure 5, the EU, Hong Kong and the United States are the three regions with the largest proportion of China's exports from 2010 to 2014. Among them, Hong Kong has the fastest growth, and the United States has grown rapidly, surpassing the EU as the country with the largest export value in China. In 2014, China accounted for the largest share of exports in Asia's major markets, followed by Vietnam and India.

\subsection{Promote Cross-Border E-Commerce Related Policies in China}

In the past few years, China's e-commerce development has maintained a growth rate of more than $20 \%$. This kind of achievement is inseparable from the strong support and high support policy of the Chinese government for e-commerce trade. As of October 2015, the National Development and Reform Commission and the State General Administration of Customs have selected Shanghai, Guangzhou, Shenzhen, Hangzhou, Ningbo, A total of nine cities, including Chongqing, Zhengzhou, Xi'an and Qingdao, conducted cross-border e-commerce service pilot projects, and promoted the development of cross-border e-commerce in China through experiments in these nine cities.

In order to better promote the development of e-commerce trade, China has intensively introduced support policies to help cross-border e-commerce development: on July 26 and August 21, 2013, the General Office of the State Council successively promoted the steady growth of import and export. Several Opinions on Structures and Opinions on Implementing Policies Related to Supporting Cross-border E-Commerce Retail Exports, in which countries have expressed strong support for cross-border e-commerce attitudes, and proposed customs, quality inspection, taxation, foreign exchange, and payment. Six measures, such as credit and credit, support the development of cross-border e-commerce. Since then, various localities have followed the national policy and introduced implementation plans. The new customs supervision model and export tax rebate policy have attracted the most attention. Since 2014, the implementation of the new policy has not only reduced the input cost of enterprises, but also stimulated the development of cross-border e-commerce trade. Since May 2015, the State Council has successively issued the "Opinions on Vigorously Developing E-Commerce

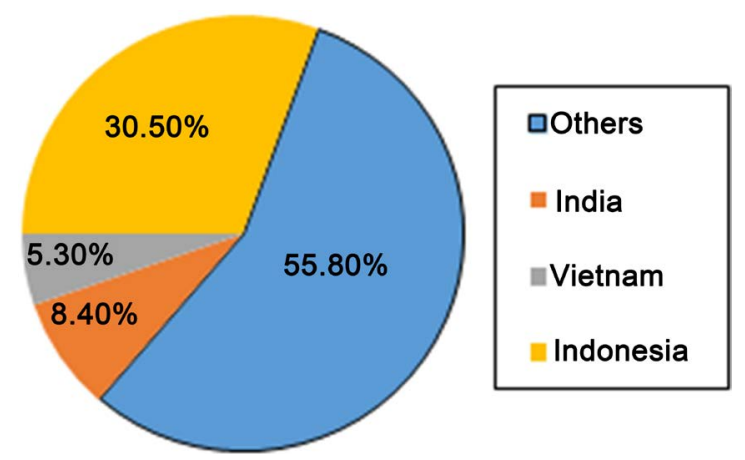

Figure 5. Distribution of China's exports in major Asian markets in 2014. 
to Accelerate the New Motive Force of the Economy" and "Several Opinions of the State Council on Accelerating the New Advantages of Foreign Trade Competition". The Ministry of Commerce has also formulated "Internet + The Circulation Action Plan further clarifies the attitude of encouraging the rapid development of e-commerce.

The cross-border e-commerce city pilot policy has been gradually explored for three years and has achieved good results. In the first three quarters of 2014, the transaction volume of e-commerce in Shanghai reached 906.6 billion yuan, a year-on-year increase of $28.1 \%$. From January to October 2014, Guangzhou's cross-border e-commerce retail (B2C) exports were 480 million yuan, and online shopping bonded (B2B/B2C) imports worth 180 million yuan, ranking first in the country. As the country's first cross-border e-commerce pilot, Hangzhou has set an example for the country's e-commerce trade area. In the two months of pilot operation in Hangzhou, the number of outbound parcels has reached 26,600 , and a total of 185 applications have been received.

\section{Innovative Development of Cross-Border E-Commerce in China}

\subsection{Innovation in Profit Model}

1) Diversification

The diversification of corporate positioning has become a new direction for corporate profit model innovation. WeChat is fully deployed in the $\mathrm{O} 2 \mathrm{O}$ field. WeChat will identify the merchants and users through QR code identification to form an SNS in the form of "acquaintances". The cooperation between TenPay and WeChat allows users to transfer money to other users via WeChat; QR code scanning is another means of WeChat payment, which can be paid immediately upon the order generation. According to relevant statistics, Metersbonwe and WeChat cooperated from the beginning to the end of December 2013. In just less than four months, Metersbonwe's WeChat membership has exceeded 700,000 . Moreover, the number of WeChat members in some stores who make orders through WeChat platform has exceeded 30\%. Nowadays, most e-commerce companies have begun to diversify their businesses, and this trend has become the only way for companies to survive and profit.

Nowadays, enterprises must carry out diversified development of profit model innovation, and they must pay more attention to the expansion of related business on the e-commerce platform while developing their own business. Joyo.com and Dangdang have had fierce competition, but Joyo has gradually changed its profit model in the years after the competition. It has broken the situation of relying solely on books for profit, increasing the category of goods, and seizing the market. Expand and upgrade opportunities, cooperate with Amazon to open up international markets. After the successful transformation, not only did not lose the previous member traffic, but attracted more people to Joyo.com to make online shopping, so that the needs of network customers can 
be better satisfied. Nowadays, Suning Tesco, Dangdang.com, Jingdong and other e-commerce companies have sold a variety of products from the very beginning to the current sales of clothing, books, electrical appliances, jewelry and so on.

2) Increase competitiveness through value-added services

Enterprises must carry out innovation in the profit model, and must strengthen and expand their own industries, and they can bring innovation to the enterprises through the "retail" to drive the profit model of their own industries. For example, the products sold on Jingdong are not monopolized and can be seen on other e-commerce websites. However, Jingdong has greatly increased its competitiveness in e-commerce with its own logistics industry, and has stood out. Another example is Amazon. Although e-commerce is in full swing, its e-commerce development has also driven its own logistics services. The most important thing is that Amazon's cloud computing revenue is very impressive. Therefore, it is possible to bring innovation to the enterprise through the "retail" to drive the profit model of its own industry.

From the point of view of sales promotion, after-sales service itself is also a means of promotion, and high-quality after-sales also enhances competitiveness for e-commerce platforms. E-commerce, represented by Jingdong, also launched a value-added service that "replaces only repairs". Once the product has a performance failure during the service period, JD will immediately replace the new machine for the consumer instead of repairing the old machine. The biggest after-sales service advantage of Vipshop is to promise unconditional return for 7 days, but when the goods are not satisfied, the consumer can make an unconditional return refund, and the postage generated by the return, Vipshop will also be refunded in the form of a voucher. Go to the consumer's Vipshop account.

3) Logistics and supply chain integration

Nowadays, the integration of logistics and supply chain has become the trend of e-commerce development and expansion. Taobao provides logistics by individual sellers. The time of logistics cannot be guaranteed. It can't deliver goods to buyers in the shortest time. Jingdong relies on its own logistics system and supply chain optimization to establish itself in major cities across the country. The Jingdong warehouse allocates the suppliers' goods to each warehouse. When the buyer needs a certain product, Jingdong can send the goods from the nearest warehouse to the seller in the shortest time by using their own logistics; Vipshop will have logistics centers in three regions: East China, South China and North China. Vipshop's unique warehousing and logistics system, namely the "mainline logistics + sub-storage + floor-to-floor" mode of logistics operation, is conducive to reducing time consumption and packaging losses, partition management, logistics service speed and quality.

In the global supply chain layout, overseas warehouses are important nodes, which integrate multiple factors such as people flow, technology flow, information flow and capital flow, and support various functions such as cross-border procurement and multinational production. In order to expand the cross-border 
e-commerce platform, on the basis of not affecting the quality of service and complying with laws and regulations, it is necessary to establish an appropriate warehouse in a timely manner and distribute it evenly in the major transaction areas. This can greatly save the time of cargo transportation, save logistics costs, improve customer satisfaction, and increase market competitiveness. SF's overseas warehouses have covered more than 200 warehouses including North America, Europe, and Russia.

\subsection{Marketing Model Innovation}

In recent years, China's cross-border e-commerce has developed rapidly, and China's foreign trade has entered a new chapter. Driven by the "Belt and Road Initiative" initiative, China's export cross-border e-commerce transactions reached 6.3 trillion yuan in 2017, a year-on-year increase of $14.5 \%$. Among them, China's export cross-border e-commerce B2B and online retail sales accounted for $80.9 \%$ and $19.1 \%$ respectively [7]. Many cross-border e-commerce companies in China have emerged rapidly. The Chinese e-commerce giants headed by Jingdong and Alibaba have led China's e-commerce trade to occupy an increasingly important position in global e-commerce trade. Among them, the marketing model of cross-border e-commerce in China has been relished by the outside world, B2B, B2C, C2C, B2M, M2C, B2A, C2A and so on. In China, the most mainstream cross-border e-commerce marketing model is $\mathrm{B} 2 \mathrm{~B}$ and B2C.

1) B2C mode

In 2007, "light in the box" was established, and it has two shopping websites, LightInTheBox and MiniInTheBox. Supporting 26 world languages, the distribution of consumers on its shopping sites is spread all over the world. At the end of 2006, "light in the box's" model of gathering was basically formed. "light in the box's" development strategy is to do cross-border B2C, promote with Google, pay with Paypal, and ship with UPS and DHL. The operation of "light in the box" Group has the following two characteristics: First, the optimization of the supply chain. Find a small factory, rely on the management and management of managers to improve production, develop a development strategy; Second, customized production services, increased many large orders. At the same time, suppliers complete the production of orders in a timely and effective manner, reducing the situation of overproduction, "light in the box" gathers with suppliers to achieve a win-win situation, and strengthen cooperation to make the factory more adaptive to the development of e-commerce.

2) Directly supply mode

In February 2014, Tmall International officially launched, providing a new way for Chinese consumers to purchase quality overseas products. The direct supply mode adopted by Tmall International requires the seller to provide the original authenticity purchased overseas on the trading platform provided by Taobao Tmall. The two sides of the transaction can talk directly on the platform, 
which is different from the traditional B2C model. The direct supply model strengthens the control of the links and reduces the cumbersome process in the transaction and logistics process.

In 2015, Hangzhou Customs will make the first cooperation attempt with Tmall International. The goods of "Hao Tao" customers will automatically pay taxes, prepaid taxes and fast customs clearance when entering the customs. After the quick customs clearance, the goods will be delivered to the consumers as soon as possible to improve efficiency.

3) B2B mode and Amazon integration

Founded in 2004, Dunhuang Network is the first trading platform for small and medium-sized suppliers in China. It is a typical B2B model. The operation of the Dunhuang network is to adopt a system that collects commissions, free of registration, and provides the latest and most professional industry information. After the transaction is completed, Dunhuang.com will charge the buyer's payment to the seller's account. Compared with Amazon, Dunhuang Network lacks its own logistics chain. In order to eliminate this problem, the logistics system of the background of Dunhuang Network is connected with UPS. The operation process has been greatly improved. However, after the order is confirmed, the UPS will automatically arrange the pick-up and automatically determine the pick-up location and the customer's consolidation. After the goods arrive on the shore, the logistics company that the customer has appointed will come to unload and transport. The entire process achieves efficient integration of logistics and is no longer limited to the traditional B2B model.

4) Mix B2B and B2C

With the development of foreign trade, it has gradually become the trend of development mode in which $\mathrm{B} 2 \mathrm{~B}$ mode and $\mathrm{B} 2 \mathrm{C}$ mode go hand in hand. The advantages of $\mathrm{B} 2 \mathrm{~B}$ mode are speed, low cost and low consumption. From the first half of 2015, the ratio of $\mathrm{B} 2 \mathrm{~B}$ transactions in China's cross-border e-commerce was 91.9\%, which was dominant; B2C accounted for $8.1 \%$. B2B has a large transaction volume and stable orders; in the $\mathrm{B} 2 \mathrm{C}$ mode, orders are fragmented and miniaturized, but demand is soaring. With the continuous development of e-commerce, the $\mathrm{B} 2 \mathrm{~B}$ and $\mathrm{B} 2 \mathrm{C}$ models have evolved from mutual opposition to gradual integration. Amazon launched B2B e-commerce platform Amazonsupply; Metro also entered B2B in China, which illustrates the mutual development and integration of $\mathrm{B} 2 \mathrm{~B}$ and $\mathrm{B} 2 \mathrm{C}$ models. In the process of e-commerce development today, the $\mathrm{B} 2 \mathrm{~B}$ and $\mathrm{B} 2 \mathrm{C}$ models will be opened to better utilize resources and improve market competitiveness.

5) Other marketing innovation models

Vipshop will be listed on the NYSE in August 2012. It is the best example of the global economic model. There are three main characteristics of Vipshop: a) Brand-name discounts, first of all, use price strategy and brand strategy to attract consumers. At the same time, due to the diversification and multi-level of brands, Vipshop's customers have a wide range of sources; b) Restricted pur- 
chase, updated every day at 10 o'clock and 22 o'clock, off-line within a week, and limited sales, while the strategy of selling out, so that consumers have the psychology of buying goods and keep the brand fresh; c) genuine insurance, authentic guarantee and The strategy of returning for seven days without reason has won the consumer's trust in Vipshop. With the above advantages as support, Vipshop will create great benefits and carry out its own optimization and development.

\subsection{Data Resources and Big Data Management}

In August 2015, the State Council issued the "Outline of Action on Promoting the Development of Big Data", which also marked the strengthening of the government's efforts to promote the data age. The key point of the two innovations is the use of data, which is a potential profit point for enterprises. The platform of big data has gradually become an indispensable data normal system. It is also closely connected with big data through traditional analysis methods. The gap between the data department and the business department of the enterprise will establish stable cooperation through data contact. relationship. The latest research in foreign countries shows that many companies pay more and more attention to the construction of big data and increase investment in the components of data. The main reason is that big data can optimize services according to the actual situation displayed by data analysis. Make important decisions such as improving user satisfaction. Tools that use data analysis and data have provided useful information for business decisions.

1) Big data chain

The data chain includes collection, aggregation, collation, analysis, conversion and application. According to the latest data, Amazon's financial report released in the first quarter of 2015 shows that Amazon AWS cloud computing services have annual revenues of US\$5 billion. E-commerce moves to data and cloud computing derived from e-commerce. Cloud computing uses idle IT resources to build elastic cloud computing and provide computing and storage lease services. Its high efficiency and low price advantage make Amazon the largest share of the global cloud computing market. Amazon launched its own cloud database service through its own data center, attracting large customers to move from their local data center to their own cloud. The large amount of data accumulated by its platform, through programmatic operation, analysis of data, has drawn conclusions and provided strong data support for later transformation and application. By strengthening the curiosity of corporate executives and employees on data, and using this curiosity to drive the growth, analysis and application of big data. In this way, the optimization of the next work is optimized.

Many cross-border platforms launch big data tools based on the needs of SMEs, providing an effective basis for their profitability and development, so they integrate and research their data. For example, Google's Google Analytics tool provides sellers with the most intuitive data through the store's lost customer analysis, natural traffic, buyer analysis and other marketing data. Another 
example is AliExpress's "data aspect" analysis tool, which includes the relevant data of the store and a large amount of industry data.

2) Data Capitalization

At present, many existing large enterprises optimize assets for their original data, and create data assets to build a data asset operation system. The key point of the establishment of an efficient data asset operation system is the standard and specification of data. This is related to the later processing analysis, and the control of data will bring effective convenience to the development of the enterprise. The Wish platform is a mobile-focused platform that collects the fragmented needs that customers have previewed when using their apps, organizes the data to understand customer preferences, and recommends relevant products to customers accordingly. The Wish platform uses the algorithm system to recommend beautiful pictures of products to customers, enhancing the user's viscosity.

Well-known companies that have already seen data analysis, such as Baidu, Google, Alibaba, Amazon, etc., are very prominent in cloud computing, which will also analyze and process the large amount of data that is silenced in cross-border e-commerce platforms. Management for effective analysis and decision making. For example, Amazon uses its own data to make the distribution of users' geographical locations in different regions, the purchase volume of different types of products, and the needs of users as one of the basis for marketing decisions, because it is necessary to establish a warehouse and its own logistics. Now, Amazon has big data to string the entire supply chain into an automated system: the timing of a purchase, the number of suppliers, and the choice of suppliers are all automatic. As a result, transportation time, transportation costs and human resources are saved, efficiency is improved, and higher economic benefits are created.

\subsection{Innovation in the Regulatory Model}

1) Relevant ministries and commissions should be integrated

The central government has promulgated a series of related measures to promote the development of cross-border e-commerce, especially the Central No. 1 document in 2015, in which the government departments have established incentive policies for e-commerce platforms involving agricultural development. All enterprises also attach great importance to agricultural products, which are the needs of institutional development, mechanism and sustainable development. Cross-border e-commerce involves a wide range of issues, including customs, inspection and quarantine, the National Development and Reform Commission, the State Ministry of Finance, the State Administration of Taxation, the People's Bank of China, the State Administration of Foreign Exchange, and the State Administration for Industry and Commerce. For example, cross-border electronic transactions in the trade between individuals, tax differences, product quality rights protection and other issues, which requires the coordination and 
joint management of the relevant departments, which can make the development of cross-border e-commerce more For health and normality.

2) Joint management of various functional departments

Recently, the State Quality Inspection Administration issued a series of documents, in which "China's cross-border e-commerce comprehensive test area inspection and quarantine declaration and release business process management procedures" stressed that China's cross-border electronic market needs to manage each other, which will be based on cross the characteristics of e-commerce are determined [8]. The inspection and quarantine department has all the business departments involved in its management. This is for the supervision and testing of goods for cross-border e-commerce, as well as for food and shelter. Each department has its own functions and has developed its own characteristics. Some standardized measures to avoid some contradictions and neglected places as much as possible.

3) Unblocking combined with long-term governance

a) Introducing the concept of "classification management"

Through analysis, it is divided into three categories: the first cross-border e-commerce is not feasible, such as negative breeding materials, and the second is to limit cross-border e-commerce, such as New Zealand's kiwi, American cherry imports, and the third is Open cross-border e-commerce, such as anti-fraud items, can be opened.

2) Take measures of "quarantine-source check", "inspection-direct release, process supervision"

Through the data analysis of cross-border e-commerce in 2015, online shopping and $\mathrm{B} 2 \mathrm{~B}$ accounted for a large proportion, and e-commerce and entry and exit could not leave the entry and exit form of bonded areas of parcels, express mail and goods. Its main form is to enter the country through air transportation. It can learn from the management mechanism of mail parcels, focusing on nuclear and biochemical prevention and control, as well as epidemic control and animal and plant epidemic diseases in the scope of health and quarantine, and investigate and prohibit the entry of prohibited items. For the detection requirements of the online shopping model for cross-border e-commerce, strict inspection is required. For the $\mathrm{B} 2 \mathrm{~B}$ model in e-commerce, the main means are supervision and control, and the means of using incentives, especially the normative detection at the time of entry and exit. For similar classification management, mails, goods, and articles belonging to the "detection scope" should be treated in an open manner, and actively released, and gradually promote the developing enterprises through the electronic management system of the uninterrupted inspection mechanism. Overseas trade development.

\section{Conclusions}

In the next 2018, based on the rapid development of China's import and export trade, experts and scholars from all over the world have been paying attention to 
the development of e-commerce in China. Under such a background, and based on the global development of e-commerce, the new situation of global e-commerce development and the innovation and development of cross-border e-commerce in China are analyzed and studied, and the following conclusions are drawn:

First, the new trend of e-commerce in China is as follows: 1) The integration of Internet companies and e-commerce companies in China, to complement each other to achieve mutual benefit and win-win; 2) Diversification of business, making consumers more diversified; 3) Trading Terminal mobility makes transactions more convenient; 4) Diversification of payment terminals to promote the development of cross-border payments.

Second, China's e-commerce innovation is manifested in: 1) Diversified development of profit model, enhancing competitiveness through integration of value-added services with logistics and supply chain; 2) Innovation of marketing model, in which B2C model is efficient in supply chain management. The mechanism requires shortening the manufacturer's purchase supply chain and achieving higher gross profit; the biggest advantage of the direct supply mode is that the link is controllable, the direct mail and distribution are simplified to the maximum extent, and the efficiency is improved; the integration of Amazon and B2B mode requires establishing its own logistics. Chain, improve efficiency to provide high-quality services; $\mathrm{B} 2 \mathrm{~B}$ and $\mathrm{B} 2 \mathrm{C}$ open, through the integration of suppliers to develop a distributor system, improve resource utilization and improve services; other marketing innovation models, with Vipshop as an example, unique marketing means and through the analysis of big data at headquarters to allocate global resources and optimize the supply chain, to deliver goods to consumers as fast as possible; 3) Data resources and big data management, to integrate information by making full use of big data Chain to realize the assetization of information and improve economic efficiency. 4) The innovation of the supervision mode should be: comprehensive management of relevant ministries and commissions. There are many types of commodities involved in cross-border electronic trade in China. All categories of departments should cooperate with each other and be strictly supervised; all functional departments should jointly manage and constrain them according to their own characteristics. Strictly crack down on and deal with counterfeit and shoddy products in the market; combined with long-term control of unblocking and blocking, it is necessary to encourage and prevent foreign goods from entering the customs, so as to prevent and combine and promote the health of China's cross-border e-commerce trade market.

\section{Conflicts of Interest}

The authors declare no conflicts of interest regarding the publication of this paper.

\section{References}

[1] Cao, S.Y. and Li, Z.X. (2013) Research on Third Party Logistics Mode of Cross-Border E-Commerce. E-Commerce, 3, 23-25. 
[2] Zhang, X.H. and Guo, H.L. (2016) Cross-Border E-Commerce and Cross-Border Logistics Collaboration: Mechanism and Path. China's Circulation Economy, 11, 83-92.

[3] Xiao, C.Z. and Bian, W.T. (2016) Thoughts on the Development of Cross-Border E-Commerce and Cross-Border Payment Services in the Context of RMB Internationalization. Zhejiang Finance, 08, 18-26.

[4] Van Hoose, D. (2011) E-Commerce Economics. Routledge, Abingdon-on-Thames, 148-152.

[5] Huajin Market Research Center (2018) China Industry Research Report Network. http://www.chinahyyj.com/

[6] Cao, L., Zhang, Z.P. and Yu, S.M. (2017) 2017 (First Half) China E-Commerce Market Data Monitoring Report. E-Commerce Research Center.

[7] Cao, L., Zhang, Z.P. and Yu, S.M. (2017) 2017 China Export Cross-Border E-Commerce Development Report. E-Commerce Research Center.

[8] Ministry of Commerce (2013) Opinions on Implementing Policies to Support Cross-Border E-Commerce Retail Exports. 